\title{
TU/e EnNHOUN

\section{Hexagonal columnar phase in 1,4-trans-polybutadiene: morphology, chain extension, and isothermal phase reversal}

\section{Citation for published version (APA):}

Rastogi, S., \& Ungar, G. (1992). Hexagonal columnar phase in 1,4-trans-polybutadiene: morphology, chain extension, and isothermal phase reversal. Macromolecules, 25(5), 1445-1452.

https://doi.org/10.1021/ma00031a014

DOI:

10.1021/ma00031a014

Document status and date:

Published: 01/01/1992

\section{Document Version:}

Publisher's PDF, also known as Version of Record (includes final page, issue and volume numbers)

\section{Please check the document version of this publication:}

- A submitted manuscript is the version of the article upon submission and before peer-review. There can be important differences between the submitted version and the official published version of record. People interested in the research are advised to contact the author for the final version of the publication, or visit the $\mathrm{DOI}$ to the publisher's website.

- The final author version and the galley proof are versions of the publication after peer review.

- The final published version features the final layout of the paper including the volume, issue and page numbers.

Link to publication

\section{General rights}

Copyright and moral rights for the publications made accessible in the public portal are retained by the authors and/or other copyright owners and it is a condition of accessing publications that users recognise and abide by the legal requirements associated with these rights.

- Users may download and print one copy of any publication from the public portal for the purpose of private study or research.

- You may not further distribute the material or use it for any profit-making activity or commercial gain

- You may freely distribute the URL identifying the publication in the public portal.

If the publication is distributed under the terms of Article $25 \mathrm{fa}$ of the Dutch Copyright Act, indicated by the "Taverne" license above, please follow below link for the End User Agreement:

www.tue.nl/taverne

Take down policy

If you believe that this document breaches copyright please contact us at:

openaccess@tue.nl

providing details and we will investigate your claim. 


\title{
Hexagonal Columnar Phase in 1,4-trans-Polybutadiene: Morphology, Chain Extension, and Isothermal Phase Reversal
}

\author{
S. Rastogi ${ }^{\dagger}$ \\ H. H. Wills Physics Laboratory, University of Bristol, Bristol BS8 1TL, U.K. \\ G. Ungar* \\ School of Materials, University of Sheffield, Sheffield S10 2TZ, U.K. \\ Received July 31, 1990; Revised Manuscript Received July 29, 1991
}

\begin{abstract}
Morphology, lamellar thickening, and the transition between the crystal and the hexagonal columnar phase were studied in 1,4-trans-polybutadiene (1,4-t-PBD) by optical and electron microscopy, time-resolved synchrotron X-ray diffraction, and DSC. It is shown for the first time that 1,4-t-PBD can form several thousand angstrom thick lamellae of the extended or nearly extended chain type. These may form either by direct growth from the melt or through annealing of thinner chain-folded lamellae, provided they are in the columnar phase. Lamellar thickness was found to increase by several hundred angstroms in solution-crystallized mats immediately upon heating above the crystal-columnar transition, which contrasts with some previous reports on single crystals of 1,4-t-PBD. In addition, a unique phase reversal was observed: the low-temperature crystal phase reappears spontaneously on annealing above the temperature of the initial transition to the high-temperature columnar phase.
\end{abstract}

\section{Introduction}

A considerable number of polymers exhibit hexagonal two-dimensionally-ordered high-temperature phases. Such polymers include polyethylene (under certain conditions), ${ }^{1}$ 1,4-trans-polybutadiene (1,4-t-PBD), 2,3 fluorinated hydrocarbon polymers, ${ }^{4,5}$ poly ( $p$-xylylene), ${ }^{6}$ substituted polysiloxanes, ${ }^{7}$ polysilanes, ${ }^{8}$ polyphosphazenes, ${ }^{9}$ poly $(n$-alkyl glutamates) ${ }^{10}$ etc.

The hexagonal mesophases are best described as calamitic columnar liquid crystals ${ }^{11}$ in which individual chains or chain stems form cylindrical columns, in contrast to discotic columnar phases ${ }^{12}$ where columns are formed through stacking of disk-like molecules. The liquid crystal nature of the hexagonal phase has been clearly demonstrated recently by the fact that, in some polymers, it occurs above the temperature range of the smectic phase. ${ }^{13}$

One important aspect of the columnar phase is that it provides the main route to extended-chain crystals. ${ }^{14,15}$ Chain extension is believed to occur readily in this phase due to the low energy barrier for molecular translation. Thus, for example, a rapid increase in the SAXS long period was observed in a time-resolved synchrotron experiment when crystals of a substituted polyphosphazene were heated above the crystal-columnar transition. ${ }^{16}$

Given that the hexagonal phase in 1,4-t-PBD was the first of its kind described in the literature and that it is stable at atmospheric pressure in a wide temperature interval, it is surprising to find no reports of thick extendedchain type lamellar crystals of this polymer, with the exception of a recent preliminary communication by one of us. ${ }^{17}$ In fact, some ambiguity exists in the literature regarding the extent of lamellar thickening in the hexagonal phase of 1,4-t-PBD. Solution-grown single crystals of this polymer, initially $100 \AA$ thick, were reported to have thickened to only $150 \AA$ when annealed above the monoclinic-hexagonal transition, i.e., in the broad temperature range between 55 and $110^{\circ} \mathrm{C} .18$ This was observed in two separate experiments. In the first, isolated monolayer lamellae, deposited on carbon film, were annealed

${ }^{\dagger}$ Present address: Physics Department, Lucknow University, Lucknow, India. and the resultant thickness was measured from the micrograph. In the second experiments, using annealed mats of sedimented crystals, lamellar thickness was measured from the line broadening of an $h k 2$ wide-angle reflection. The SAXS long period could not be measured as no SAXS peak was observed in annealed mats.

The relatively small reported increase in crystal thickness from 100 to $150 \AA$ is at odds with the large shift of $14{ }^{\circ} \mathrm{C}$ in the monoclinic-hexagonal transition temperature, $T_{\mathrm{t}}$, observed with mats that had been heated above the transition temperture of the original crystals. ${ }^{18}$ An unreasonably high fold-surface free energy $\sigma_{\mathrm{e}}$ would have to be invoked to reconcile these observations.

The present study was undertaken as an attempt to clarify the apparent controversy about the extent of lamellar thickening in the columnar phase of 1,4-t-PBD. It involves optical and electron microscopical observation of lamellar morphology developed during growth from the melt and during subsequent isothermal annealing. We also report annealing experiments on mats of solutiongrown single crystals, using thermal analysis and electron microscopy. Further, we describe real-time X-ray scattering experiments, both in the small-angle (SAXS) and wide-angle (WAXS) region, using synchrotron radiation. Strong evidence is provided for rapid and pronounced lamellar thickening and chain extension occurring in the columnar phase of 1,4-t-PBD. Additionally, we report an unusual observation of phase reversal: the low-temperature phase spontaneously reappears on annealing above the temperature of the initial transition from the low- to the high-temperature phase.

\section{Experimental Section}

1,4-t-PBD was kindly supplied by Prof. P. J. Lemstra and made available to us through Prof. A. Keller. The polymer had $99 \%$ trans content and an $M_{w}$ of 75000 . Optical microscopical observation of lamellar growth from the isotropic melt was performed in polarized light using a Zeiss Ultraphot microscope and a Mettler FP82 hot stage. Specimens for transmission electron microscopy were prepared as follows. After crystallization from the melt or solution for a selected period at temperature $T_{c}$, the specimen is quenched in ice water and then fractured in liquid nitrogen. Subsequently, permanganic etch- 

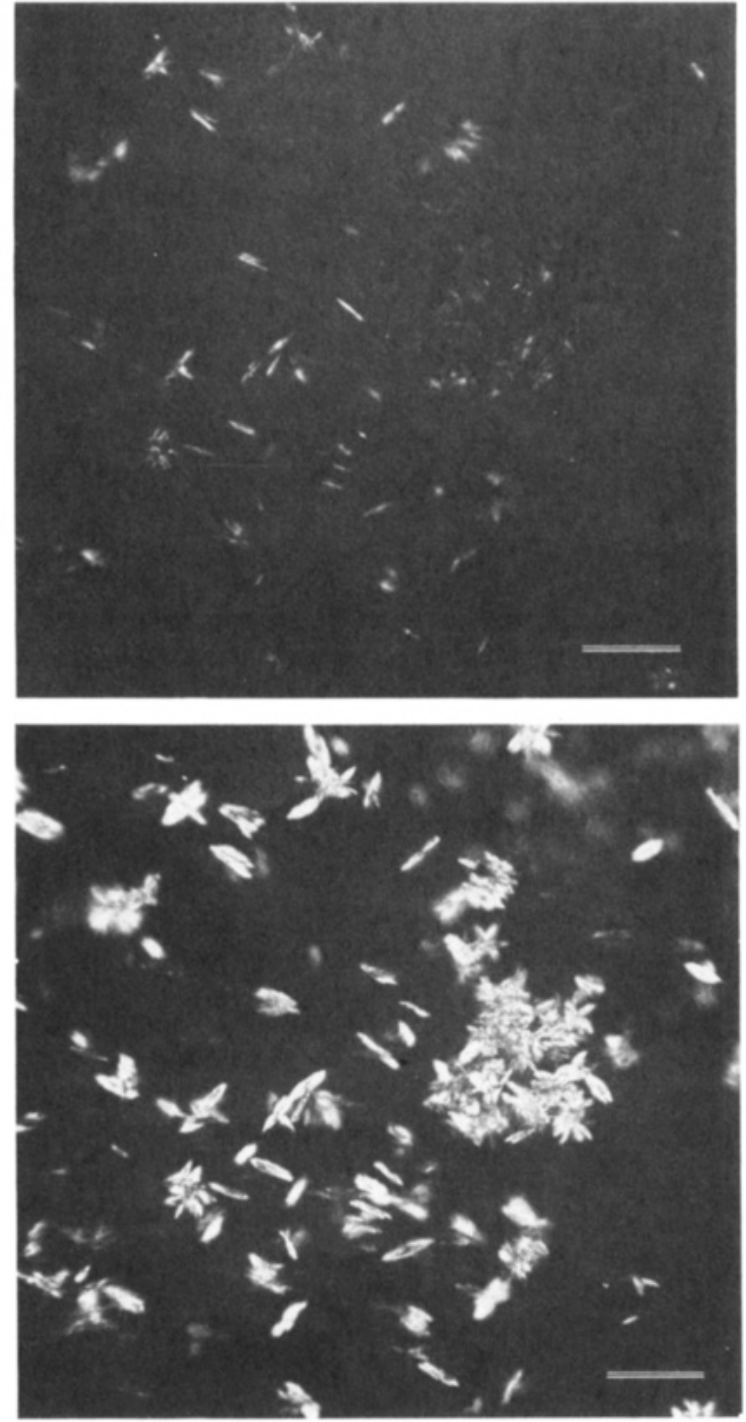

Figure 1. Optical micrographs showing isothermal growth of hexagonal columnar domains of 1,4-t-PBD from isotropic melt at $136{ }^{\circ} \mathrm{C}$ : (a) after $5 \mathrm{~min}$; (b) after $30 \mathrm{~min}$. Crossed polars. Scale bar $=50 \mu \mathrm{m}$.

ing ${ }^{19}$ is applied, the etching solution found best suited for 1,4t-PBD being a 5:2:2 mixture of $\mathrm{H}_{2} \mathrm{SO}_{4}, \mathrm{H}_{3} \mathrm{PO}_{4}$, and water with an addition of $1 \mathrm{wt} \%$ of $\mathrm{KMnO}_{4}$. The two-stage replica technique was applied, using $\mathrm{Pt} / \mathrm{Pd}$ and carbon shadowing.

Single crystals were grown from heptane solution at $25^{\circ} \mathrm{C}$. The sedimented mats were filtered and dried in vacuo. Samples were stored under nitrogen, and antioxidant was added to the solution to avoid degradation. All experiments involving single crystals were carried out on the same mat. Thermal analysis was performed on a Perkin-Elmer DSC-7 instrument.

Time-resolved X-ray diffraction work was carried out using the synchrotron at Daresbury, U.K. A one-dimensional positionsensitive detector was used. The beam cross-section was only 1 $\mathrm{mm} \times 0.3 \mathrm{~mm}$ in the detector plane; hence no slit desmearing was needed. Crystal mats were enclosed in Lindemann glass capillaries, which were wrapped in aluminum foil and positioned in a modified Mettler hot stage. For SAXS experiments the mats were lying edge-on to the beam and normal to the detector. For WAXS experiments the mats were facing the beam flat-on.

\section{Results}

Morphology of Columnar Lamellae Grown at Low Supercooling. Parts a and b of Figure 1 show polarized optical micrographs of 1,4-t-PBD cooled from the isotropic melt to $T_{\mathrm{c}}=136^{\circ} \mathrm{C}$ and then kept isothermally at that temperature for 5 and $30 \mathrm{~min}$, respectively. For reference we note that the extrapolated equilibrium temperature of
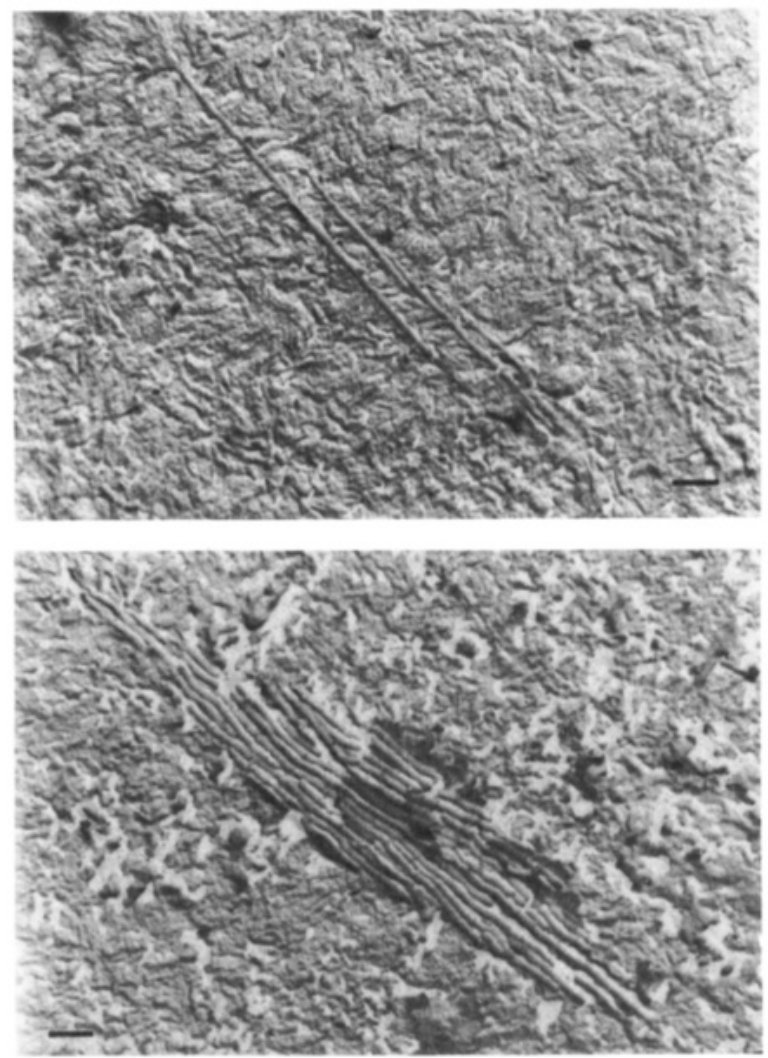

Figure 2. Electron micrographs of 1,4-t-PBD partially crystallized in the columnar phase at $138.4^{\circ} \mathrm{C}$ and then quenched. Sections through two lamellar stacks are shown, one at an early (a) and the other at a more advanced stage of formation (b). Scale bar $=1 \mu \mathrm{m}$.

the columnar-isotropic transition (the "melting" point) for 1,4-t-PBD is $145^{\circ} \mathrm{C}$, according to Finter and Wegner. ${ }^{20}$ As is common in the case of hexagonal phases in polymers (e.g., in polyetylene at high pressures, ${ }^{14}$ in poly(diethylsiloxane), ${ }^{15}$ in cis-polyisoprene, ${ }^{21}$ etc.), elongated birefringent platelets are seen to form at an early stage (seen as thin rods when viewed edge-on) (Figure 1a). These subsequently grow into fairly large $(>20 \mu \mathrm{m})$ oval leafshaped objects (Figure 2b). We do not exclude the possibility that these are in fact circular, as in poly(trifluoroethylene $)^{22}$ or, as recently found, in polyethylene. ${ }^{23}$ However, circular shape could only be observed if the platelets were viewed flat-on, in which case they would not be visible due to zero birefringence.

Clustering of platelets is common even in the early stages of development of the columnar phase. Edge-on view of larger platelets indicates tapering at borders, which is another feature often found in hexagonal phases of other polymers. A thicker central portion is also indicated by the frequently observed central dark band (see Figure 1b); this is due to the coincidental extinction where the phase difference between ordinary and extraordinary rays amounts to $180^{\circ}$.

Optical textures developed at other temperatures were very similar to that at $136^{\circ} \mathrm{C}$, the scale being slightly finer for lower $T_{\mathrm{c}}$ 's.

Electron microscopy was performed on replicas of fractured and etched specimens after "crystallization" for a given time at $T_{\mathrm{c}}$ followed by quenching in ice water. In this way the morphology of the comparatively large crystals formed via the hexagonal phase at $T_{\mathrm{c}}$ can be clearly seen against the featureless background formed on quenching. Parts a and b of Figure 2 show, respectively, an early and a more advanced stage of formation of lamellar stacks at 


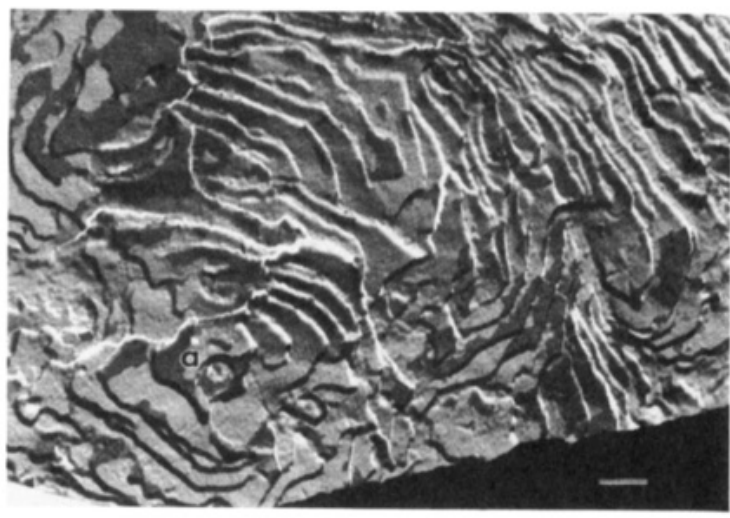

Figure 3. Flat-on view of lamellar terraces grown at $137.5^{\circ} \mathrm{C}$. A screw dislocation is marked with a. Scale bar $=1 \mu \mathrm{m}$.

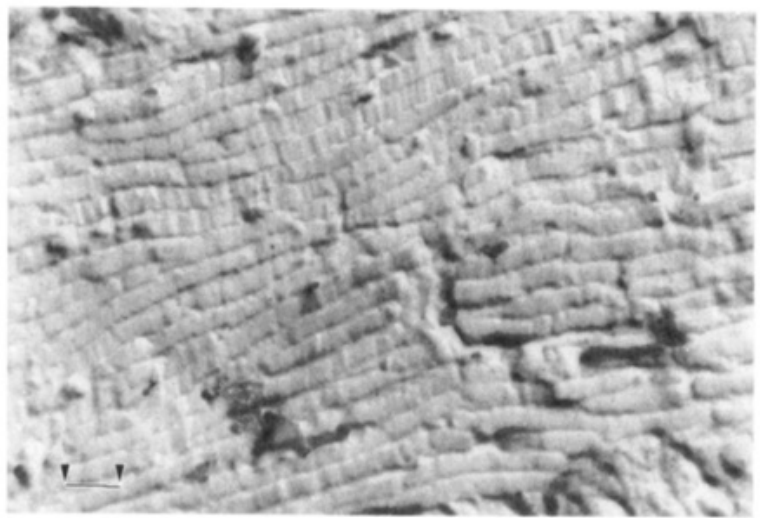

Figure 4. Higher magnification edge-on view of a lamellar stack of 1,4 -t-PBD grown at $138.4{ }^{\circ} \mathrm{C}$ for $48 \mathrm{~h}$. Marker $=0.5 \mu \mathrm{m}$.

$T_{\mathrm{c}}=138.4^{\circ} \mathrm{C}$. The lamellae are seen edge-on and are 0.2 $\mu \mathrm{m}$ thick. These and other similar micrographs suggest that an isolated lamella appears first, with multiple new layers apparently forming on both sides of it. Such morphology is indicative of spiral growth, for which there is further evidence from flat-on views of lamellar stacks such as that in Figure 3. As a matter of fact, a screw dislocation, marked a, is also observed in Figure 3.

If the optical and the electron micrographs in Figures 1 and 2 are compared, it becomes clear that each birefringent leaf-shaped platelet is in fact a stack of a number of individual lamellae. Tapering of platelets observed optically bears no direct relation to tapering of individual lamellae, but rather it is caused by their reduced number at borders of the stacks (see Figure 2b).

A close-up of a lamellar stack grown at $138.4^{\circ} \mathrm{C}$ is shown in Figure 4. The lamellae are ca. $2500 \AA$ thick and have perpendicular striations, typical of "extended-chain" crystals.

Morphology of Columnar Lamellae Grown at Intermediate Supercooling. Since the lamellae nucleate and grow slowly at low supercoolings, it is not clear whether their thickness as observed for example in Figure 4 is determined by their primary formation or by subsequent isothermal thickening. The two processes can, however, be more easily separated at larger supercoolings. Thus, for example, the initial thickness of the lamellae grown at $128^{\circ} \mathrm{C}$ is ca. $500 \AA$ (see Figure 5a). Subsequent isothermal annealing increases this thickness considerably, as shown in Figure 5b. In addition, lamellar stacking becomes less regular, a feature observed in all annealing experiments on this polymer (see below).

The thickening process at $128^{\circ} \mathrm{C}$ is diagrammatically shown in Figure 6. The wide error bars for the annealed samples indicate the wide spread of thicknesses as measured from the electron micrographs. It is the higher
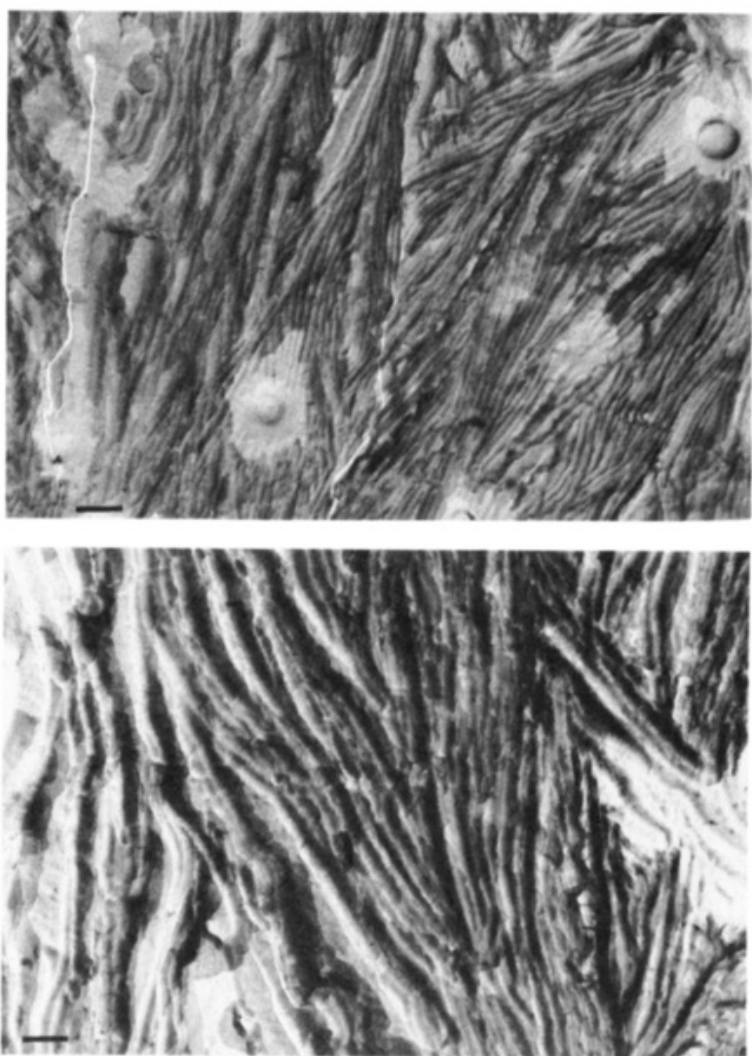

Figure 5. Electron micrographs of 1,4-t-PBD lamellae grown isothermally at $128^{\circ} \mathrm{C}$ for (a) $5 \mathrm{~min}$ and (b) $120 \mathrm{~min}$. Scale bar $=0.3 \mu \mathrm{m}$.

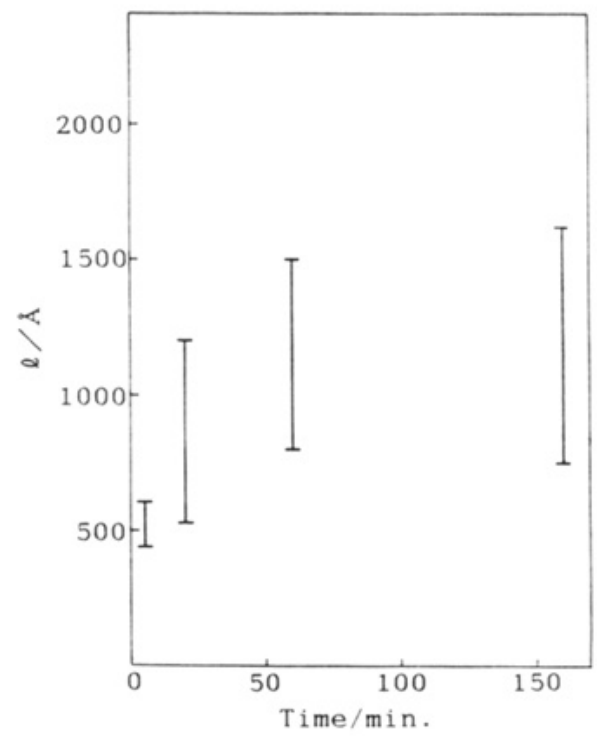

Figure 6. Lamellar thickness, measured from electron micrographs, as a function of "crystallization" time at $128^{\circ} \mathrm{C}$. Large error bars indicate spread of observed values.

thickness value for any particular annealing time that is more relevant for the thickening kinetics. Lower values are believed to be a result mainly of sterical obstruction to thickening in an already close-packed system, i.e., to lamellar impingement during growth in the chain direction. ${ }^{24,25}$

Lamellar Thickening in Solution-Crystallized 1,4t-PBD. The DSC heating thermogram of the as-prepared mat of solution-grown single crystals (Figure 7) shows a single monoclinic-hexagonal (crystal-columnar) transition endotherm at $66^{\circ} \mathrm{C}$, indicating that the temperature of solution crystallization was low enough for all crystals to grow under the same regime with uniform thickness. It 


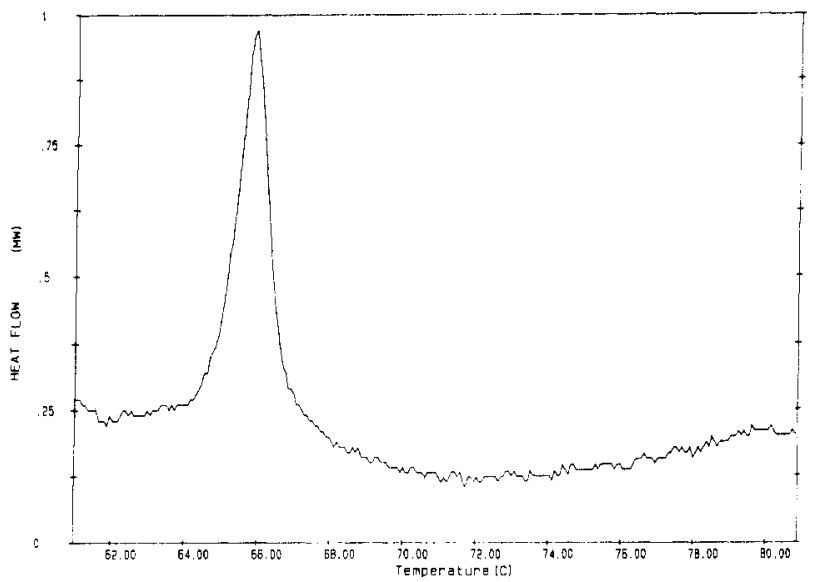

Figure 7. DSC heating thermogam of solution-crystallized 1,4$t$-PBD showing the monoclinic crystal-hexagonal columnar phase transition. Heating rate $1^{\circ} \mathrm{C} / \mathrm{min}$.

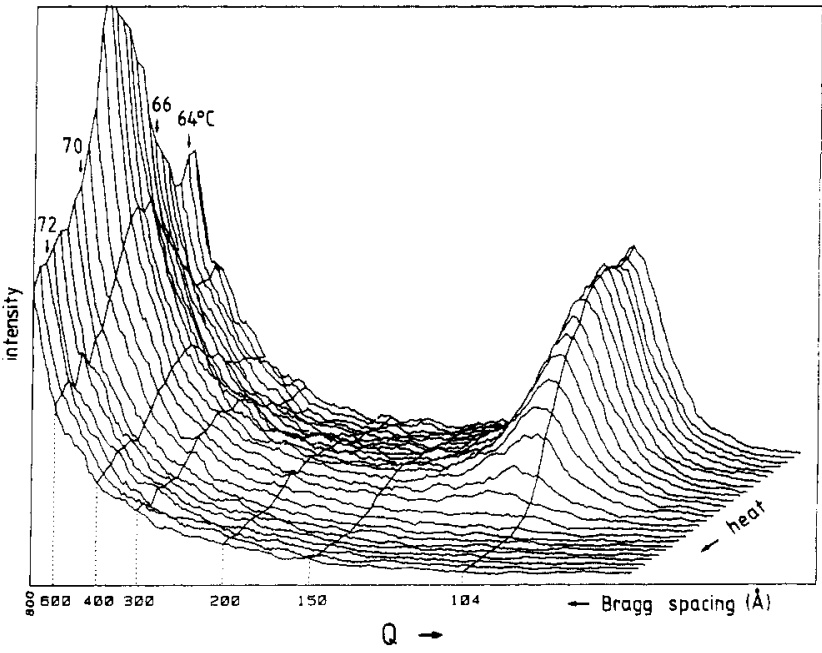

Figure 8. Series of synchrotron SAXS curves recorded during heating a single-crystal mat of $1,4-\mathrm{t}-\mathrm{PBD}$ at $3^{\circ} \mathrm{C} / \mathrm{min}$ through the monoclinic-hexagonal transition. Each curve covers $8 \mathrm{~s}$ or $0.4^{\circ} \mathrm{C}$.

should be mentioned that, under certain conditions, two different crystal thicknesses are obtained in the same preparation. ${ }^{20,26}$ The transition endotherm in Figure 7 is, in fact, remarkably sharp, with full width at half-height (fwhh) being only $1^{\circ} \mathrm{C}$. Considering that $T_{\mathrm{t}}$ is a steep function of lamellar thickness in the $100-\AA$ range (see below), the sharpness of the endotherm is attributed to a narrow distribution of lamellar thicknesses (fwhh $<8 \AA$ ).

To observe changes in the SAXS pattern upon the monoclinic-hexagonal transition, time-resolved scattering curves were recorded during a constant heating rate scan of 1,4$t$-PBD crystals at $3^{\circ} \mathrm{C} / \mathrm{min}$. The sequence of traces is shown in Figure 8. The sharp first-order SAXS diffraction peak of the original crystal mat corresponds to a long period $l$ of $104 \AA$. Upon the crystal-columnar transition at $T_{\mathrm{t}}=$ $66^{\circ} \mathrm{C}$ the sharp peak indeed disappears rather than shifts to lower scattering angles, in agreement with the report by Takayanagi et al. ${ }^{18}$ However, Figure 8 clearly shows that the gap between the original SAXS peak at $104 \AA$ and the central scatter fills in at the transition and that scattering at very low angles intensifies.

As heating continues above $68^{\circ} \mathrm{C}$ the newly emerged scattering in the medium to large $l$ region disappears again.

In another experiment heating was interrupted at 66 ${ }^{\circ} \mathrm{C}$, the actual transition temperature, and changes to the SAXS curve were followed isothermally. The traces thus recorded, after background subtraction, are shown in Figure 9. Again, the disappearance of the $104-\AA$ peak is

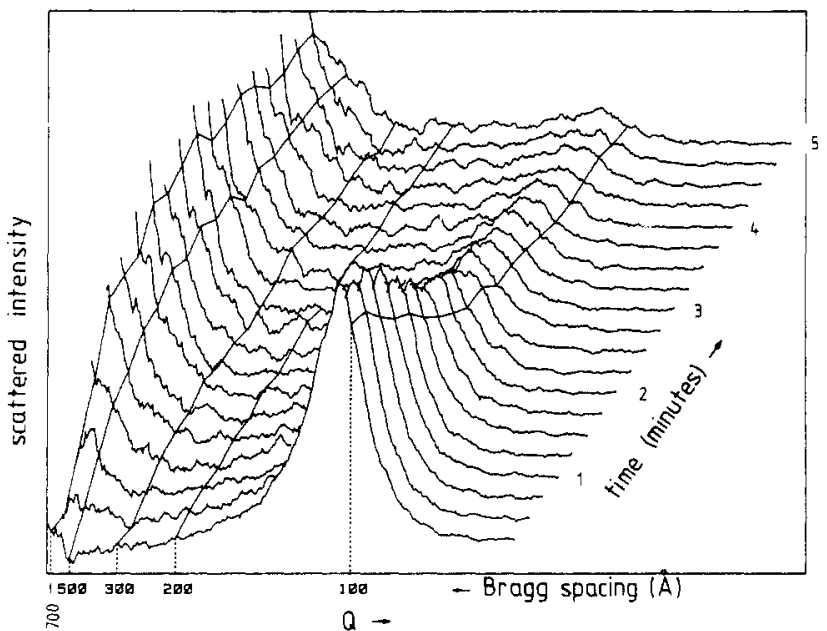

Figure 9. Time evolution of the SAXS curve, recorded isothermally at $66^{\circ} \mathrm{C}$, the transition temperature of the present crystals. Times elapsed since reaching $T_{\mathrm{t}}$ (in minutes) are marked on the right. Central scatter increases simultaneously with the decrease of the 104-A peak. A background of the form $(a q+b)^{-m}$ $+c$, fitted to the first curve, was subtracted from all traces in this figure.

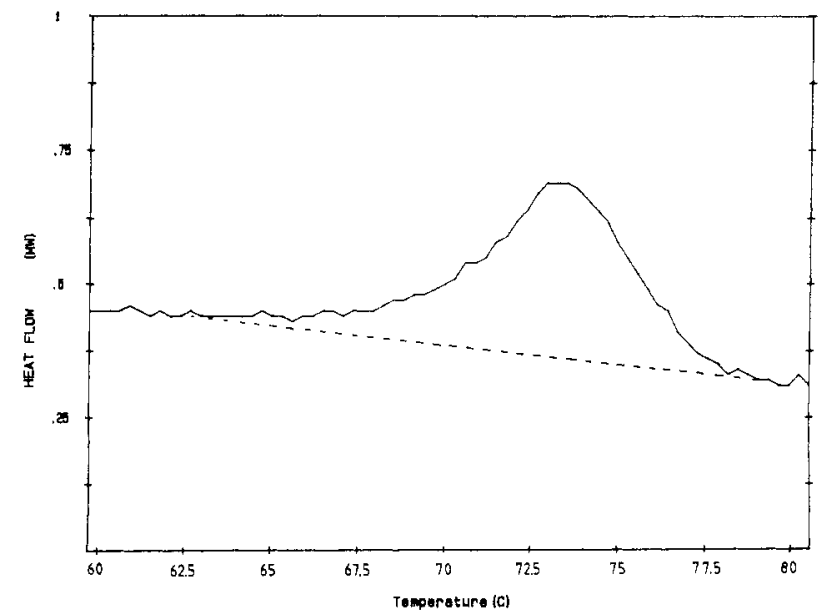

Figure 10. Crystal-columnar transition endotherm of a singlecrystal mat previously heated at $3{ }^{\circ} \mathrm{C} / \mathrm{min}$ to $73^{\circ} \mathrm{C}$ (as in the SAXS experiment in Figure 8) and immediately cooled to room temperature. Compare with endotherm in Figure 7. Heating rate $1^{\circ} \mathrm{C} / \mathrm{min}$.

accompanied by an increase in the scatter at very low angles.

Parallel annealing experiments were performed by DSC. Figure 10 is the crystal-columnar transition endotherm of a single-crystal sample which had been subjected to the same heating program as that of the SAXS experiment in Figure 8; i.e., the original mat was heated through the transition at $3{ }^{\circ} \mathrm{C} / \mathrm{min}$ up to $73^{\circ} \mathrm{C}$ and then cooled to room temperature. The resulting endotherm recorded on subsequent reheating (Figure 10) is considerably broader than the original endotherm in Figure 7 (note that the tempertaure scale is the same in all thermograms shown, i.e., Figures 7, 10, and 12) and the peak temperature of the former is raised by $8{ }^{\circ} \mathrm{C}$. The increased $T_{\mathrm{t}}$ indicates significant lamellar thickening (see Discussion), while the broadening of the peak indicates broadening of the distribution of lamellar thicknesses, in line with the SAXS result.

Replicas for electron microscopy were difficult to prepare in the case of single-crystal mats, as these tended to disintegrate in the process. However, annealing well above $T_{\mathrm{t}}$ provided sufficient cohesion to overcome the problem. A micrograph of a mat of solution-grown crystals annealed 


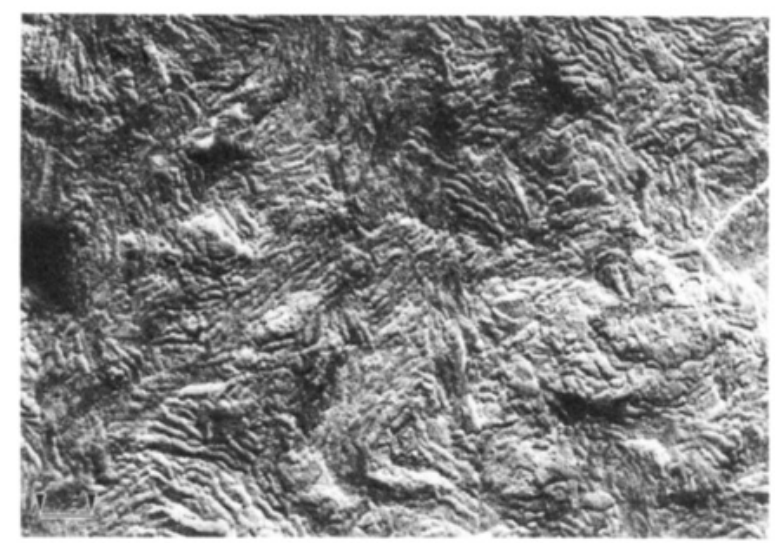

Figure 11. Electron micrograph of a mat of solution-grown single crystals of $1,4-\mathrm{t}-\mathrm{PBD}$ annelaed at $116^{\circ} \mathrm{C}$ for $40 \mathrm{~min}$. Marker $=$ $1 \mu \mathrm{m}$.

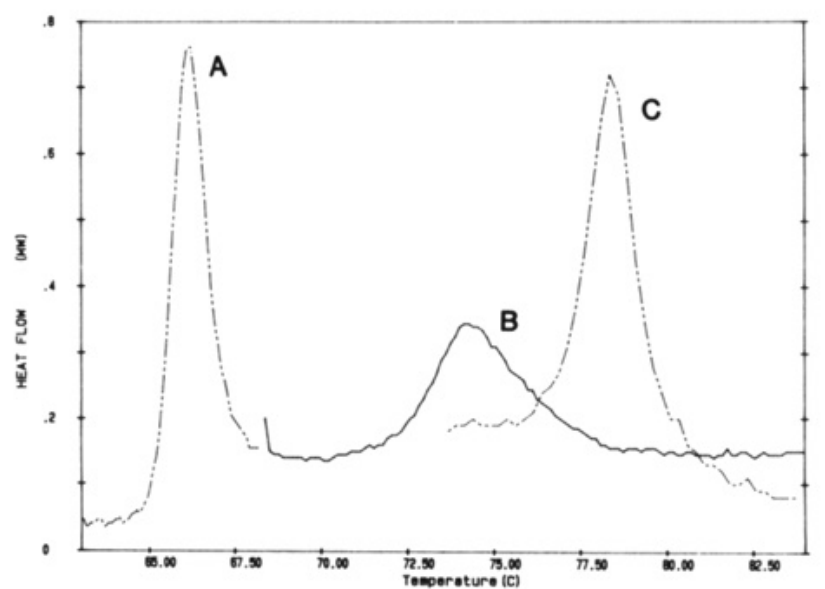

Figure 12. DSC annealing experiment showing isothermal phase reversal. The single-crystal mat is first heated through the original crystal-columnar transition and heating is stopped at 68 ${ }^{\circ} \mathrm{C}$ (endotherm A). Heating is resumed after isothermal annealing at $68^{\circ} \mathrm{C}$ for $12 \mathrm{~h}$. The new broad endotherm (endotherm $\mathrm{B}$ ) is attributed to the second crystal-columnar transition of the material that had isothermally retransformed into the monoclinic crystal during annealing at $68^{\circ} \mathrm{C}$. Thermogram $\mathrm{C}$ is shown for comparison and was obtained after a 12-h annealing of the original mat at $82^{\circ} \mathrm{C}$, i.e., just above $T_{t}^{\circ}$. Heating rate $1^{\circ} \mathrm{C} / \mathrm{min}$.

at $116^{\circ} \mathrm{C}$ for $40 \mathrm{~min}$ is shown in Figure 11. Lamellar periodicity, measured from edge-on stacks, is of the order of $1500 \AA$. Thus the layer thickness has increased 15-fold on annealing.

Isothermal Phase Reversal. Since $T_{\mathrm{t}}$ in 1,4-t-PBD is a steeply increasing function of lamellar thickness at small $l$ 's, ${ }^{20}$ the possibility was recognized that solutiongrown crystals, brought to just above $T_{\mathrm{t}}$ and left to thicken, might revert isothermally to the monoclinic crystal phase as $T_{\mathrm{t}}$ rises above the annealing temperature $T_{\mathrm{a}}$. This proposition is first tested by DSC; see Figure 12. The sample is first heated to $T_{\mathrm{a}}=68^{\circ} \mathrm{C}$. The endotherm recorded during this heating stage, with the peak at $66^{\circ} \mathrm{C}$, shows that the entire sample has transformed into the columnar phase (cf. Figure 7). After $12 \mathrm{~h}$ of annealing at $T_{\mathrm{a}}=68^{\circ} \mathrm{C}$, heating is resumed without lowering the temperature below $T_{\mathrm{a}}$. The thermogram recorded during this second heating stage (full line in Figure 12) again shows the crystal-columnar transition endotherm. The reemerged endotherm has an area $85 \%$ the area of the original peak, suggesting that $85 \%$ of the material had reverted to the crystalline state on annealing at $T_{\mathrm{a}}=68$ ${ }^{\circ} \mathrm{C}$. The new transition endotherm has a maximum at 74 ${ }^{\circ} \mathrm{C}$ and is asymmetrically broadened toward high temperatures.

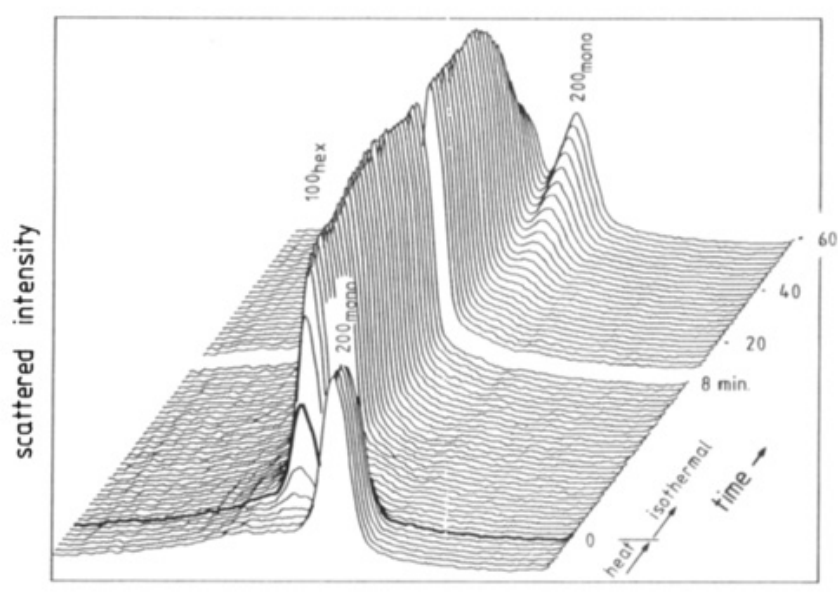

$Q \rightarrow$

Figure 13. Wide-angle X-ray diffraction experiment showing isothermal phase reversal. Time-resolved scattering traces show the angular region of the main monoclinic $\left(200_{\text {mono }}\right)$ and hexagonal $\left(100_{\text {hex }}\right)$ reflections. The single-crystal mat is heated at $3^{\circ} \mathrm{C} / \mathrm{min}$ to $68.5^{\circ} \mathrm{C}$ (emphasized curve), and after that the temperature remained constant to within $\pm 0.1^{\circ} \mathrm{C}$. Separation between time frames is $15 \mathrm{~s}$ for the first 37 curves and $2 \mathrm{~min}$ for the last 25 curves. Overall elapsed time since reaching $68.5^{\circ} \mathrm{C}$ (in minutes) is marked on the right. Monoclinic $\rightarrow$ hexagonal transition is seen at the beginning and the reverse hexagonal $\rightarrow$ monoclinic transition toward the end of the run.

For comparison, another single-crystal sample from the same mat was annealed at a somewhat higher temperature of $82^{\circ} \mathrm{C}$ for $12 \mathrm{~h}$. No endothermic peak is observed on further heating from $T_{\mathrm{a}}$, indicating that the sample remained in the hexagonal phase throughout the annealing. In a second experiment a portion of the original mat was annealed under identical conditions $\left(82^{\circ} \mathrm{C}\right.$ for $12 \mathrm{~h}$ ), but it was then cooled to room temperature and subjected to a subsequent heating DSC scan. The peak temperature $\left(78.5^{\circ} \mathrm{C}\right)$ of the transition endotherm thus recorded $(\mathrm{C}$, Figure 12) is rather close to $T_{\mathrm{t}}$ of infinitely thick crystals (see Discussion).

An experiment analogous to the DSC annealing immediately above the temperature of initial transition was also performed by wide-angle X-ray diffraction. The originally monoclinic single-crystal mat was heated to 68.5 ${ }^{\circ} \mathrm{C}$. After this the temperature remained constant. Figure 13 shows the corresponding wide-angle diffractograms in the region of the main diffraction peaks of the monoclinic and hexagonal phases. The emphasized curve marks the end of heating and the beginning of the isothermal stage of the experiment. This coincides with the monoclinichexagonal transition, as shown by the disappearance of the $200_{\text {mono }}$ peak and the appearance of the $100_{\text {hex }}$ peak. During the first $20 \mathrm{~min}$ or so of the isothermal stage there is no change in the WAXS pattern, but after that the monoclinic 200 peak starts reappearing and the $100_{\text {hex }}$ peak starts disappearing (note the change in time scale after 8 min of annealing in Figure 13). Thus the $\mathrm{X}$-ray experiment confirms that the reverse monoclinic-hexagonal transition indeed occurs on isothermal annealing above the temperature of the original forward monoclinic-hexagonal transition.

\section{Discussion}

General Comments. Electron micrographs of crystals grown in the columnar phase at low supercooling (Figures $2-5$ ) and the diagram in Figure 6 clearly show that the thickness of the lamellae is considerably greater than is usually observed in melt-crystallized polymers (e.g., typically $200-400 \AA$ in polyethylene).

The morphology seen in 1,4-t-PBD is, in fact, characteristic of that formed via the two-dimensionally-ordered 
columnar phase (e.g., in polyethylene at elevated pressure or poly (diethylsiloxane) or, in some cases, via the threedimensional conformationally disordered (condis) crystalline phase (e.g., poly(chlorotrifluoroethylene) ${ }^{17,27}$ ). Both types of phases are believed to have high molecular mobility compared to the ordered crystal. The translatory chain mobility is thought to enable the initially thin chain-folded lamellae to thicken to near-equilibrium size. An alternative mechanism, proposed for the evolution of thick isolated layers, entails true three-dimensional growth, i.e., one which includes addition of uncrystallized material through the top and bottom faces of the lamellae. ${ }^{25}$

In the case of 1,4-t-PBD, thick lamellae have not been reported ${ }^{28}$ in spite of the existence of the hexagonal columnar phase in a wide interval of $70^{\circ} \mathrm{C}$ above the range of the ordered crystal at atmospheric pressure. In this respect 1,4-t-PBD has appeared to be an anomaly. However, the present work shows that 1,4 -t-PBD is not exceptional and that lamellae as thick as $0.2 \mu \mathrm{m}$ are readily formed either through initial formation or through subsequent annealing in the hexagonal columnar phase.

The present work also demonstrates the qualitative difference in mobility between the crystalline (monoclinic) and the columnar (hexagonal) phase: while no change in morphology occurs in the former over extended annealing periods at any temperature, rapid lamellar thickening takes place in the latter phase even at the lowest temperature at which it exists, particularly in the case of initially thin solution-grown crystals. The extensive thickening involved can lead to unusual effects, such as isothermal phase reversal.

The individual points are discussed in more detail below.

Morphology of Melt-Grown 1,4-t-PBD. The "rock wall" appearance of the fracture surface in Figure 4, showing the lamellae grown at low supercooling edge-on, is very similar to the morphology of polyethylene formed at high pressure. ${ }^{29}$ The striations normal to lamellar planes indicate the chain direction. In both cases (1,4-t-PBD and polyethylene) initial lamellar growth occurs in the hexagonal phase, whereas the EM specimens are prepared after transformation to true crystal on cooling. It is possible that the striations originate from grain boundaries created by this transformation.

The thickness of the lamellae in Figure 4 is $0.25 \mu \mathrm{m}$. In comparison, the contour length of the weight-average molecule is about twice as large; thus such a molecule is not fully extended. However, due to the considerable width of the molecular weight distribution of the present polymer, a sizeable proportion of chains can be accommodated into the $0.25-\mu \mathrm{m}$ crystals in the fully extended conformation.

Appearance of spiral growth (Figures $2 \mathrm{~b}$ and 3 ) and screw dislocations (Figure 3 ) is an unusual feature in columnar liquid crystals and liquid crystals in general. These features are not seen in mesophases of low molecular weight compounds or in more conventional (nematic and smectic) mesophases in polymers. Their origin in the polymeric columnar phase is believed to be the same as the origin of lamellar morphology itself: the chain stems traversing the columnar domain are straight and parallel, and hence growth occurs predominantly laterally, by deposition of new chains, rather than longitudinally. In principle, the situation is the same as with polymer crystals; in this respect it is of little consequence that, in the columnar phase, there is no long-range order in the position of monomer repeat units in the chain direction. ${ }^{11}$ In the case of both crystalline and columnar phase, screw dislocations and growth spirals are not based on crystallographic layers as in low moleccular weight crystals, but rather on superstructural lamellae of a kinetically determined thickness.

SAXS and Lamellar Thickening. Our SAXS results (Figures 8 and 9 ) show that, as soon as the single crystals of 1,4-t-PBD are brought above the crystal-columnar transition temperature $T_{\mathrm{t}}$, rapid morphological changes take place, leading to an immediate disappearance of the 104-A diffraction peak and to its replacement by diffuse low-intensity scattering at lower angles. The fact that no discrete SAXS peak is observed above $T_{\mathrm{t}}$ is attributed to two factors: (a) to a loss of correlation in density fluctuations, i.e., to a wide distribution of lamellar thicknesses and, possibly, irregular stacking after the transition, and (b) to a lowered value of the SAXS invariant.

The second reason (b) for the loss of the SAXS peak above $T_{t}$ can arise either from an increased degree of "crystallinity" of the polymer or from reduced density of the columnar phase with respect to the crystalline phase. Both effects cause a decrease in the overall scattered SAXS intensity, expressed as the invariant $Q$ :

$$
Q=(\pi / 2) \int I(q) q^{2} \mathrm{~d} q=\phi(1-\phi)\left(\rho_{c}-\rho_{\mathrm{a}}\right)^{2}
$$

Here $I$ is the scattered intensity, $q$ is the wavevector, $\phi$ is the crystallinity or, more generally, the volume fraction of one of the two phases present, and $\rho_{\mathrm{c}}$ and $\rho_{\mathrm{a}}$ are the respective densities of the crystalline (or columnar) phase and the amorphous phase. Dilatometric measurements by Tatsumi et al..$^{18}$ have shown that the changes in density upon the monoclinic-hexagonal and hexagonal-melt transitions of 1,4-t-PBD are approximately equal. Thus ( $\rho_{\text {hex }}$ $\left.-\rho_{\mathrm{a}}\right)=(1 / 2)\left(\rho_{\text {mono }}-\rho_{\mathrm{a}}\right)$ and, according to $(1)$, the expected SAXS intensity above $T_{\mathrm{t}}$ is only $1 / 4$ that below $T_{\mathrm{t}}$. As again found by Tatsumi et al., ${ }^{18}$ crystallinity $\phi$ of singlecrystal mats of 1,4-t-PBD increases when heated above $T_{t}$ and, since initially $\phi>0.5$, the $\phi(1-\phi)$ factor decreases. Thus, above $T_{\mathrm{t}}$ the invariant is reduced on account of both lowered $\left(\rho_{\mathrm{c}}-\rho_{\mathrm{a}}\right)$ and lower $\phi(1-\phi)$.

Nevertheless, even though reduced in intensity, the sharp 104- $\AA$ diffraction peak would still be present above $T_{\mathrm{t}}$ if no other morphological changes were induced by the monoclinic-hexagonal transition. Hence the coherence in density fluctuation must have been lost almost instantly above $T_{t}$, which, in turn, can only be explained by inhomogeneous rapid lamellar thickening. The increase in the diffuse low-angle scattering above $T_{\mathrm{t}}$, seen in Figures 8 and 9 , is in agreement with this interpretation.

Additional experimental support for a rapid increase, and loss of uniformity, in lamellar thickness comes from DSC and, to some degree, from electron microscopy.

Lamellar Thickening and the Transition Temperature. Unlike the SAXS method, measurement of lamellar thicknesses via the transition temperature $T_{\mathrm{t}}$ does not depend on regularity of lamellar stacking. The dependence of $T_{\mathrm{t}}$ on lamellar thickness $l$ is given by the following relationship: 26

$$
T_{\mathrm{t}}=T_{\mathrm{t}} \cdot\left[1-\frac{2\left(v^{\mathrm{m}} \sigma_{\mathrm{e}}^{\mathrm{m}}-v^{\mathrm{h}} \sigma_{\mathrm{e}}^{\mathrm{h}}\right)}{l \Delta h_{\mathrm{t}}}\right]
$$

where $T_{\mathrm{t}}^{\circ}$ is the equilibrium transition temperature of infinitely thick crystals, $v^{\mathrm{m}}$ and $v^{\mathrm{h}}$ are specific volumes of the two phases, $\sigma_{e}{ }^{m}$ and $\sigma_{e}{ }^{h}$ are their end-surface free energies, and $\Delta h_{t}$ is the transition enthalpy per unit mass. Finter and Wegner ${ }^{20}$ obtained the following experimental relationship for the dependence of $T_{\mathrm{t}}$ on $l$ in 1,4-t-PBD:

$$
T_{\mathrm{t}}=T_{\mathrm{t}}^{\circ}-1.29 \times 10^{-5} / l(\mathrm{~cm})
$$

According to Figure $8 \mathrm{a}$ of ref $20, T_{\mathrm{t}}{ }^{\circ}=80.2^{\circ} \mathrm{C}$. 
Equation 3 is utilized below to obtain independent information on lamellar thickness. However, we digress briefly at this point to derive the relationship between end-surface free energies $\sigma_{\mathrm{e}}{ }^{\mathrm{m}}$ and $\sigma_{\mathrm{e}}^{\mathrm{h}}$. From the depression of the isotropization temperature of thin lamellae of crosslinked 1,4-t-PBD, the above authors found $\sigma_{\mathrm{e}}^{\mathrm{h}}=1.9 \times$ $10^{-2} \mathrm{~J} \mathrm{~m}^{-2}$ (=19 $\left.\mathrm{erg} \mathrm{cm}^{-2}\right)$. If one now substitutes into eq 2 the values for $v^{\mathrm{m}}$ and $v^{\mathrm{h}}$ from ref 18 and those for $\sigma_{\mathrm{e}}^{\mathrm{h}}$ and $\Delta h_{\mathrm{t}}\left(144 \mathrm{~J} \mathrm{~g}^{-1}\right)$ from ref 20 , one obtains $\sigma_{\mathrm{e}}{ }^{\mathrm{m}}$ as $4.7 \times 10^{-2}$ $\mathrm{J} \mathrm{m}^{-2}$ (=47 $\left.\mathrm{erg} \mathrm{cm}^{-2}\right)$. It follows that the end-surface free energy of the columnar-amorphous interface is $40 \%$ that of the crystal-amorphous interface.

From Figures 7 and 10 it can be seen that $T_{t}$ of single crystals increases considerably (from 65.9 to $73.7^{\circ} \mathrm{C}$, peakto-peak) after being subjected to the heating cycle equivalent to the one in the SAXS experiment in Figure 8. The new endotherm (Figure 10) is broad, indicating substantial nonuniformity in lamellar thicknesses. This is in agreement with the loss of the discrete low-angle X-ray diffraction peak. According to eq 3 the measured increase in peak $T_{\mathrm{t}}$ means an increase in lamellar thickness from 90 to $200 \AA$. The temperature corresponding to the upper limit of the broad endotherm is $77.8^{\circ} \mathrm{C}$, which corresponds to $l$ values between 500 and $600 \AA$.

Crystals annealed in the columnar phase at higher temperatures show endotherms having $T_{\mathrm{t}}$ practically coincident with $T_{t}{ }^{\circ}$. This indicates that lamellar thicknesses in excess of $1000 \AA$ are achieved, in agreement with the results of electron microscopy (Figure 11).

Electron Microscopy and Lamellar Thickening. The micrograph in Figure 11 shows single crystals annealed at $116^{\circ} \mathrm{C}$. Edge-on sections of lamellar stacks reveal an average layer thickness of the order of $1500 \AA$.

Lamellar periodicity appears somewhat nonuniform in Figure 11. Nevertheless, a discrete X-ray diffraction peak would be expected from such a sample in the region of very low angles, outside the resolution limit of our SAXS equipment. Judging by the narrow SAXS peak and the existence of higher orders for the unannealed mat (not shown in Figures 8 and 9), it would seem that the regularity of stacking deteriorates on annealing. The lack of a discrete SAXS peak at shorter annealing times and at lower $T_{\mathrm{a}}$ (Figures 8 and 9), together with the broadness of the corresponding endotherm (Figure 10), suggests that the nonuniformity in lamellar thickness is largest in the early stages of annealing in the columnar phase.

The loss of stacking regularity is also evident from the observation on lamellae isothermally melt-grown and annealed at $120^{\circ} \mathrm{C}$ (see Figure $5 \mathrm{~b}$ ). In addition to interlamellar variation, there is considerable variation in thickness within a single lamella, a feature particularly prominent in annealed single crystals (Figure 11).

Finally, we comment on the apparent discrepancy between the presently observed multiple increase in lamellar thickness in 1,4-t-PBD annealed above $T_{\mathrm{t}}$ and the modest increase from 100 to $150 \AA$ reported by Tatsumi et al. ${ }^{18}$ As mentioned in the Introduction, lamellar thickness in the multilayer crystal precipitate was measured by the latter authors from the line widths of nonequatorial reflections. The low value of $150 \AA$ for the dimension of annealed crystals in the chain direction was, in our opinion, probably caused by the neglect of line broadening due to lattice (e.g., paracrystalline) distortion. It is recalled that the columnar phase has no long-range order in the chain direction, and thus considerable distortion may be trapped in monoclinic crystals cooled below $T_{\mathrm{t}}$ after annealing in the columnar phase. On the other hand, the thickness of $150 \AA$ measured by EM on annealed monolayer crystals on carbon substrate ${ }^{18}$ is no doubt genuine. However, thickening of isolated polymer

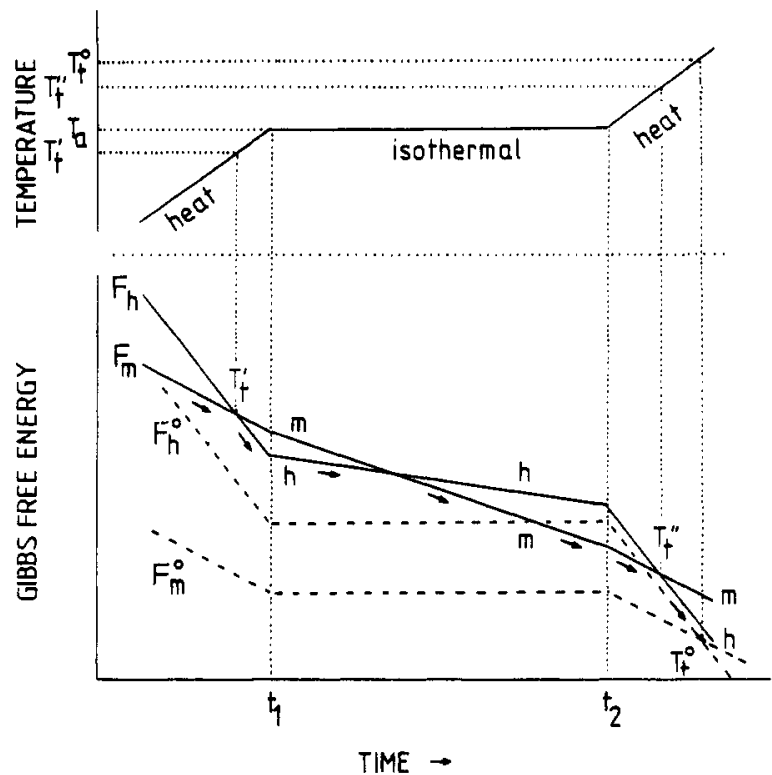

Figure 14. Schematic representation of the DSC experiment in Figure 12 (curves $A$ and $B$ ), explaining the isothermal phase reversal in terms of the free enthalpies of the monoclinic (crystal) lamellae, $F_{m}$, and the hexagonal (columnar) lamellae, $F_{h}$, of finite thickness. $F_{m}{ }^{\circ}$ and $F_{b}{ }^{\circ}$ refer to domains of infinite size. Arrows mark the actual pathway of the system in this experiment. Temperature program is shown at the top of the diagram. For further explanation see text.

crystal lamellae is known in general to occur much less readily than that of multilayer lamellar stacks, due to the need for macroscopic transport of matter.

Phase Reversal. The reappearance of the monoclinic form after annealing above the temperature of the original monoclinic-hexagonal transition is discussed next. This unique occurrence is clearly a consequence of lamellar thickening in the hexagonal phase and of the pronounced increase in $T_{\mathrm{t}}$ with lamellar thickness $l$.

In our annealing experiment shown in Figures 12 and 13 , crystals with $l=104 \AA$ were brought into the columnar phase just above $T_{\mathrm{t}}$. However, during isothermal annealing at $T_{\mathrm{a}}$ the lamellae have thickened and $T_{\mathrm{t}}$ increased above $T_{\mathrm{a}}$, so that the supercooling $T_{\mathrm{t}}-T_{\mathrm{a}}$ of the columnar phase became sufficient for the reverse columnar-crystal transition to occur. The transition endotherm of the isothermally recrystallized polymer (Figure 12, curve $B$ ) is rather broad, with a peak temperature higher by $8^{\circ} \mathrm{C}$ than that of unannealed crystals (curve $\mathrm{A}$ ) and having a high-temperature tail extending to $77.5^{\circ} \mathrm{C}$, which is $11.5^{\circ} \mathrm{C}$ above the original $T_{\mathrm{t}}$. According to eq 3 this means that the annealing has produced a broad distribution of $l$ values, ranging from ca. $220 \AA$ (peak) to $750 \AA$ (tail end).

The annealing experiment in Figure 12, curves $A$ and $B$, is schematically represented in free enthalpy-time coordinates in Figure 14. The full lines represent, respectively, the free enthalpies of the actual monoclinic and hexagonal lamellae, $F_{\mathrm{m}}$ and $F_{\mathrm{h}}$, while the dashed lines denote the free enthalpies $F_{\mathrm{m}}{ }^{\circ}$ and $F_{\mathrm{h}}{ }^{\circ}$ of the two phases with infinite dimensions. For a given lamellar thickness the free enthalpies are related through

$$
\frac{F_{\mathrm{m}}-F_{\mathrm{m}}^{\circ}}{F_{\mathrm{h}}-F_{\mathrm{h}}^{\circ}}=\frac{\sigma_{\mathrm{e}}^{\mathrm{m}}}{\sigma_{\mathrm{e}}{ }^{\mathrm{h}}}=\frac{47}{19} \approx 2.5
$$

In the first heating stage of our experiment, up to the time $t_{1}, F_{\mathrm{h}}$ falls below $F_{\mathrm{m}}$ at the temperature $T_{\mathrm{t}}{ }^{\prime}$, and the first $\mathrm{m} \rightarrow \mathrm{h}$ transition occurs. Nevertheless, $F_{\mathrm{h}}{ }^{\circ}$ still remains above $F_{\mathrm{m}}{ }^{\circ}$. During the isothermal annealing, between $t_{1}$ and $t_{2}$, both $F_{\mathrm{m}}$ and $F_{\mathrm{h}}$ continue decreasing as lamellae thicken, with $F_{\mathrm{m}}$ decreasing 2.5 times faster than $F_{\mathrm{h}}$. Thus, 
at some stage, $F_{\mathrm{m}}$ falls again below $F_{\mathrm{h}}$ and the reverse h $\rightarrow \mathrm{m}$ phase transition occurs isothermally. In the third stage of the DSC experiment (the WAXS experiment in Figure 13 was confined to the first two stages only), heating is resumed and $F_{\mathrm{h}}$ decreases below $F_{\mathrm{m}}$ for the second time; a $\mathrm{m} \rightarrow \mathrm{h}$ transition occurs once again, this time at a higher temperature $T_{\mathrm{t}}{ }^{\prime \prime}$.

It would appear that for annealing temperatures only slightly above the initial $T_{\mathrm{t}}$, i.e., for $T_{\mathrm{t}}^{\prime}<T_{\mathrm{a}}<T_{\mathrm{t}}{ }^{\circ}$, lamellar thickening is self-limiting: as soon as the phase reversal into the monoclinic crystal occurs, thickening stops. This would explain why, even after $12 \mathrm{~h}$ of annealing, the $l$ distribution still peaks only at around $220 \AA$ in our DSC experiment while, at the same time, annealing at a somewhat higher temperature $T_{\mathrm{a}}=82^{\circ} \mathrm{C}$ results in l's in the range of $1000 \AA$, as determined from thermogram $C$, Figure 12. This latter annealing, of course, does not produce the phase reversal, since now $T_{\mathrm{a}} \geq T_{\mathrm{t}}{ }^{\circ}$. The difference in resulting $l$ values between the two annealings is far too large to be attributed to the mere difference in $T_{\mathrm{g}}$ of $14^{\circ} \mathrm{C}$, as these annealing temperatures are still $60-70^{\circ} \mathrm{C}$ below the isotropization point. The comparatively small increase in $l$ at $T_{\mathrm{a}}=68^{\circ} \mathrm{C}$ is attributed to the fact that columnar lamellae which had achieved a certain thickness recrystallize and thus lose the ability for further thickening.

Finally, it should be realized that the current phenomenon of phase reversal differs essentially from the situation where thin crystalline polymer lamellae (e.g., polyethylene single crystals) are heated just above their melting point and where the isotropic melt thus produced is still sufficiently supercooled to allow recrystallization of thicker lamellae. In such a case the thickness of the new lamellae is determined by crystallization kinetics at the particular crystallization temperature. In contrast, in the present experiment on 1,4-t-PBD recrystallization ocurs from the columnar liquid crystal and the thickness of the resultant crystals is fixed by the thickness of the precursor columnar lamellae.

\section{Conclusions}

In summary, the principal results of the present study are as follows:

(a) As in other polymers exhibiting the hexagonal columnar phase, lamellae thicker than 0.1 or $0.2 \mu \mathrm{m}$ are readily obtained in 1,4-t-PBD. These can form in the columnar phase either (1) directly, at low supercooling, from the isotropic melt or (2) through annealing of thinner lamellae which were originally grown either in the columnar or in the crystalline (monoclinic) phase.

(b) Each birefringent leaf-shaped platelet, observed by optical microscopy during the development of the columnar phase, is shown by electron microscopy to be in fact a stack of a number of individual lamellae. Tapering of platelets at edges, observed optically, bears no relation to tapering of individual lamellae, but rather it is caused by their reduced number at borders of the stacks. Growth spirals and screw dislocations occur in the columnar phase, in spite of it being a liquid crystalline state where such phenomena are not normally observed.

(c) Large increase in lamellar thickness, to several hundred angstroms, occurs in solution-crystallized mats of 1,4-t-PBD immediately upon the crystal-columnar transition. The morphological change, as recorded by realtime SAXS, takes place even more rapidly than in the columnar phase of poly[bis ( $p$-methylphenoxy)phosphazene] observed in a similar experiment. ${ }^{16}$ Thickening in 1,4-t-PBD is, in certain cases, accompanied by a considerable loss of lamellar periodicity.

(d) On annealing in a limited range above the original transition temperature, the high-temperature hexagonal phase reverts to the low-temperature monoclinic crystal. This unique phase reversal is a consequence of the substantial lamellar thickening in the columnar phase and of the pronounced lamellar thickness dependence of the transition temperature.

Acknowledgment. The 1,4-trans-polybutadiene used was supplied by Professor P. J. Lemstra for Professor A. Keller's crystallization experiments at Bristol. We are grateful to Professor Keller for handing over some of the material and for helpful discussions. S.R. thanks the Science and Engineering Research Council for financial support.

\section{References and Notes}

(1) Bassett, D. C. In Developments in Crystalline Polymers; Bassett, D. C., Ed.; Applied Science: London, 1982; Vol. 1.

(2) Natta, G.; Corrandini, P. Nuovo Cimento 1960, 15 (Suppl. 1), 9.

(3) Suehiro, K.; Takayanagi, M. J.Macromol.Sci., Phys. 1970, B4, 39.

(4) Clark, E. S.; Muus, L. T. Z. Kristallogr. 1962, 117, 119. Clark, E. S. J. Macromol. Sci., Phys. 1967, B1, 795.

(5) Miyamoto, Y.; Nakafuku, C.; Takemura, T. Polym. J. 1972, 3, 120.

(6) Isoda, S.; Kawaguchi, A.; Katayama, K.-I. J.Polym. Sci.,Polym. Phys. Ed. 1984, 22, 669.

(7) Godovsky, Yu. K.; Papkov, V. S. Adv. Polym. Sci. 1989, 88, 129

(8) Lovinger, A. U.; Schilling, F. C.; Bovey, F. A.; Zeigler, J. M. Macromolecules 1986, 19, 2660.

(9) Kojima, M.; Magill, J. H. Polymer 1989, 30, 579.

(10) Watanabe, J.; Ono, H.; Uematsu, I.; Abe, A. Macromolecules $1985,18,2141$.

(11) Ungar, G. Polymer, submitted.

(12) Destrade, C.; Foucher, P.; Gasparoux, H.; Tinh, N. H.; Levelut, A. Mol. Cryst. Liq. Cryst. 1984, 106, 121.

(13) Ungar, G.; Feijoo, J. L.; Percec, V.; Yourd, R. Macromolecules $1991,24,953$.

(14) Bassett, D. C. Polymer 1976, 17, 460

(15) Papkov, V. S.; Svistunov, V. S.; Godovsky, Y. K.; Zhdanov, A. A. J. Polym. Sci., Polym. Phys. Ed. 1987, 25, 1858.

(16) Magill, J. H.; Riekel, C. Makromol. Chem., Rapid Commun. 1986, 7, 287.

(17) Hikosaka, M.; Tsukijima, K.; Rastogi, S.; Keller, A.; Kawabata, H.; Komazawa, T. Polym. Prepr. (Am. Chem. Soc., Div. Polym. Chem.) 1989, 30 (2), 307.

(18) Tatsumi,T.; Fukushima, T.; Imada, K.; Takayanagi, M.J.Macromol. Sci., Phys. 1967, B1, 459.

(19) Olley, R. H.; Hodge, A. M.; Bassett, D. C. J. Polym. Sci. Polym. Phys. Ed. 1979, 17, 627.

(20) Finter, J.; Wegner, G. Makromol. Chem. 1981, 182, 1859.

(21) Phillips, P. J.; Edwards, B. C. J. Polym. Sci., Polym. Phys. Ed. $1976,14,377 ; 1976,14,39$

(22) Lovinger, A. J.; Cais, R. E. Macromolecules 1984, 17, 1939.

(23) DiCorleto, J. A.; Bassett, D. C. Polymer 1990, 31, 1971

(24) Rastogi, S.; Kawabata, H.; Hikosaka, M.; Keller, A. Macromolecules, in press.

(25) Hikosaka, M.; Kawabata, H.; Keller, A.; Rastogi, S. J. Macromol. Sci., Phys., in press.

(26) Marchetti, A.; Martuscelli, E. J. Polym. Sci., Polym. Phys. Ed. $1976,14,323$.

(27) Miyamoto, Y.; Nakafuku, C.; Takemura, T. Polym. J. 1972, 3, 122

(28) Wunderlich, B.; Moeller, M.; Grebowicz, J.; Baur, H. Adv. Polym. Sci. 1988, 87, 1 .

(29) Wunderlich, B.; Arakawa, T. J. Polym. Sci. 1964, A2, 3697.

Registry No. 1,4-t-PBD, 9003-17-2. 